\title{
EPISTEMOLOGIA E EDUCACC̃̃O ÉTNICO-RACIAL: ANÁLISE DOS MANUAIS DIDÁTICOS DO ENSINO FUNDAMENTAL DE MARIANA-MG
}

\author{
EPISTEMOLOGY AND ETHNIC-RACIAL EDUCATION: ANALYSIS OF TEXTBOOKS \\ OF THE ELEMENTARY SCHOOL OF MARIANA-MG
}

\author{
EPISTEMOLOGÍA Y LA EDUCACIÓN ÉTNICA-RACIAL: ANÁLISIS DE LOS LIBROS \\ DE TEXTO DE LA ESCUELA PRIMARIA MARIANA-MG
}

Marcelo Donizete da Silva* marmaio1970@gmail.com

\author{
REVISTA PEDAGÓGICA \\ Revista do Programa de Pós-graduação em Educação da Unochapecó | ISSN 1984-1566 \\ Universidade Comunitária da Região de Chapecó | Chapecó-SC, Brasil \\ Como referenciar este artigo: SILVA, M. D. Epistemologia e Educação étnico-racial: análise dos manuais \\ didáticos do Ensino Fundamental de Mariana-MG. Revista Pedagógica, Chapecó, v. 19, n. 40, p. 172-195, \\ jan./abr. 2017. DOI: http://dx.doi.org/10.22196/rp.v19i40.3749
}

RESUMO: Este artigo tem como objetivo analisar as teorias educacionais contemporâneas e seus desdobramentos no processo de difusão da cultura étnico-racial. Buscou-se desenvolver um estudo criterioso sobre os manuais didáticos de História do Brasil e Língua Portuguesa do Ensino Fundamental. A metodologia desenvolvida foi de análise bibliográfica acerca das teorias que congregam a proposta política e pedagógica dos parâmetros curriculares nacionais (PCNs), no que é referente à história da cultura Africana e sua interface com a educação brasileira, e esta análise será desenvolvida no campo, no contexto das escolas de Mariana/Minas Gerais (MG). O referencial teórico é de cunho histórico-crítico que envolve as áreas de: Teorias e História da Educação do Negro no Brasil. Espera-se com esta pesquisa contribua com a análise crítica sobre: a História do Negro no Brasil; seus desdobramentos ideológicos no tocante à formação da população negra; na perspectiva emancipadora das relações étnico-raciais no país; e na crítica à leitura ideológica da educação proposta pelas teorias educacionais.

Palavras-chave: História do Negro na Educação. Políticas Educacionais. Epistemologia e Educação. Ciências da Educação.

ABSTRACT: This article aims to analyze about the contemporary educational theories and their unfolding in the process of diffusion of the ethnic-racial culture. We tried to develop a careful study on the didactic manuals of History of Brazil and Portuguese Language of Elementary School. The methodology developed was a bibliographical analysis about the theories that bring together the political and pedagogical proposal of the national curricular parameters (NCPs) in what refers to the history of African culture and its interface with Brazilian education, and this analysis will be developed in the field, in the context of the schools of Mariana/ Minas Gerais (MG). The theoretical reference is of a historical-critical nature that involves the areas of: Theories and History of Black Education in Brazil. It is hoped that this research contributes with the critical analysis on: the History of the Negro in Brazil; Ideological developments in the formation of the black population; In the emancipatory perspective of ethnic-racial relations in the country; And in critique the ideological reading of education proposed by educational theories.

Keywords: Black History in Education. Educational Policies. Epistemology and Education,.Educational Sciences.

RESUMEN: Este artículo tiene como objetivo analizarlas teorías educativas contemporáneas y sus consecuencias en el proceso de difusión de la cultura étnica-racial. Hemos tratado de desarrollar un estudio cuidadoso de los libros de texto de historia de Brasil y Lengua Portuguesa de la Escuela Primaria. La metodología desarrollada fue de la naturaleza bibliográfica de las teorías que reúnen a la propuesta política y pedagógica de los parámetros curriculares nacionales (PCN) en lo que se relaciona con la historia de la cultura africana y su interrelación con la educación brasileña, e el análisis se desarrollara en el campo, en el contexto de las escuelas de Mariana/ Minas Gerais (MG).. El marco teórico de las áreas circundantes de la naturaleza histórico-crítica: teoría e Historia de la Educación Negro en Brasil. Se espera que esta investigación contribuya al análisis crítico de 


\begin{abstract}
* Possui graduação em Filosofia pela Pontifícia Universidade Católica de Campinas (1994), Mestrado (2003) e Doutorado (2010) em Educação pela Faculdade de Educação da UNICAMP. Atuou como: Professor da Educação Básica (Ensino Médio) na Secretaria Estadual do Estado de São Paulo; Coordenador do Curso de Licenciatura em Filosofia nas modalidades a Distância (EaD), Presencial e Pós Graduação (Lato Sensu) do Centro Universitário Claretiano de Batatais (CEUCLAR), Professor, Substituto, no Departamento de Educação do Instituto de Biociências da UNESP no Campus Rio Claro-SP; Professor Titular e Tutor a Distância do Centro Universitário Claretiano de Batatais e Chefe do Departamento de Educação do Instituto de Ciências Humanas e Sociais da Universidade Federal de Ouro Preto. Atualmente é Professor do Departamento de Educação do Instituto de Ciências Humanas e Sociais da Universidade Federal de Ouro Preto (DEEDU/ICHS/UFOP).
\end{abstract}

la Historia de los negros en Brasil; sus desarrollos ideológicos con respecto a la formación de la población negro; la perspectiva emancipatoria de las relaciones étnico-raciales en el país; y una crítica de la lectura ideológica de la educación propuesta por teorías educativas.

Palabras clave: Negro y su Historia en la Educación. Políticas Educativas. Epistemología y Educación. Ciencias de la Educación.

\section{INTRODUÇÃO}

Atualmente, o desenvolvimento das pesquisas em educação tem-se debruçado em estudos acerca dos paradigmas das ciências, que são apresentados como fomentadores de uma "nova" prática pedagógica. Nesse artigo, a proposta, no que se refere à produção do pensamento e da ciência educacional, será a de discutir sobre o método de ensino e sua configuração com o debate acerca das teorias que fazem parte do contexto escolar e sua articulação com o debate acerca das questões étnico-raciais. Nesse sentido, entende-se que, para o contexto da educação brasileira, uma análise acerca das teorias educacionais contemporâneas se faz necessária, na medida em que se pensam as transformações do trabalho docente, bem como a formação do sujeito para o exercício da cidadania.

No rol das teorias contemporâneas que aprofundam o debate sobre os paradigmas educacionais destaca-se, de modo especial, o paradigma emergente da complexidade de Moraes (2008), apresentado como anunciador das transformações educacionais, deste tempo. Isso significa considerar que, toda forma de compreensão da educação estaria ligada às formas de constituição dos novos paradigmas, fato que "levaria" à transformação das relações sociais. No entanto, nessa produção de uma realidade aparente da problemática escolar, as teorias em questão, constituem o contrário do que proclamam, ou seja, nada mais são do que anunciadoras da produção de uma pseudoconcreticidade, segundo Kosik (2002), deste processo.

$\mathrm{Na}$ análise de Alves (2008) acerca da questão exposta, principalmente no que se refere à chamada democratização dos sistemas educacionais, o autor comenta que:

Ao frisar a necessidade de politização dos educadores especialistas de nosso tempo, toca-se algo essencial que tem passado, pela repetição acrítica, por uma banalização perniciosa: trata-se da formação do educador para o exercício da cidadania. Tornou-se lugar comum o reconhecimento de que a formação básica assumiu a condição de elemento central na educação do trabalhador, inclusive daqueles que exercem atividades de ensino. Se essa é a tendência, cabe uma consideração mais detida sobre o seu significado, em especial porque a formação básica passou a ser admitida, tacitamente também, como uma necessidade imanente à educação de todos os cidadãos. Logo, sob pena de 
1 O grande desafio da escola é investir na superação da discriminação e dar a conhecer a riqueza representada pela diversidade etnocultural que compõe o patrimônio sociocultural brasileiro, valorizando a trajetória particular dos grupos que compõem a sociedade. Nesse sentido, segundo os Parâmetros Curriculares Nacionais: Apresentação dos Temas Transversais Ética, a escola deve ser local de diálogo, de aprender a conviver, vivenciando a própria cultura e respeitando as diferentes formas de expressão cultural (BRASIL, 1997, p. 27). transformar-se num chavão, numa expressão vazia de sentido e abstrata, emerge a necessidade de afirmar-se o conteúdo da formação para a cidadania. Essa formação é um processo que implica não somente uma prática cidadã fundada na imitação dos demais cidadãos. Se, em todas as épocas, a dimensão da imitação exerceu um expressivo papel na formação do homem, hoje por si ela não basta. Sobretudo para o decantado "exercício consciente da cidadania”, o homem carece de entendimento acerca de como funciona a sociedade. (ALVES, 2008, p. 108).

Sobre os eixos estruturais desta análise, cuja discussão se assenta na questão epistemológica da educação, é necessário compreender os seus impactos na realidade escolar. Desse modo, o que se pretende analisar aqui partirá dos seguintes questionamentos: como as teorias educacionais, imbuídas na proposta do material didático são absorvidas na escola, de modo especial nas escolas periféricas? Quais os seus impactos na formação da consciência dos jovens quanto à sua condição histórico social? Como essas teorias influenciam na produção do pensamento dos jovens que se encontram marginalizados do processo social na realidade Mariana (Cidade que será o lócus para análise do objeto)?

Entende-se que esses impactos podem ser anunciadores de discursos que legitimam os processos de dominação que perduram, historicamente, na realidade escolar e, por sua vez, mantêm intactas as formas de exclusão social. Dessa forma, buscar compreender as questões estruturais das teorias educacionais poderá auxiliar na compreensão destas no processo de formação da consciência dos jovens, principalmente quanto ao trabalho disposto nos materiais didáticos.

Com o avanço das políticas neoliberais, torna-se perceptível que a produção das teorias ainda carregam ranços da ideologia dominadora, que massificam a grande maioria da população negra de nossa realidade. Logo, o estudo dos "manuais didáticos", na sua relação educativa, significa apresentar a problemática assentada na matriz teórica proposta para a elaboração dessa temática e que se coloca como vanguarda no processo de organização do pensamento pedagógico brasileiro.

As políticas de ação-afirmativa têm assentadas a sua base conceitual nas análises e propostas das teorias educacionais contemporâneas, e é, nesse sentido, que a proposta de reforma política do Estado teve como principal eixo de organização, a compensação das dividas históricas da educação para com o povo brasileiro.

Os debates acerca das questões raciais presentes nos temas transversais ${ }^{1}$ em especial o que está disposto nos materiais didáticos, não deixam transparecer a problemática histórica da formação da consciência social da sociedade brasileira. Nesse sentido, a defesa 
sobre os conceitos - e não a análise da problemática histórica - tem as suas repercussões na situação presente no contexto escolar. Essa questão evidencia que a população tem os seus direitos garantidos pelas políticas de ação afirmativa, mas ainda se encontram distantes do processo de equalização das relações sociais. Faz-se necessário explicitar que, para os avanços da pesquisa em educação e do desenvolvimento das tecnologias, a discussão da didática e dos processos da organização histórico social do povo Negro é questão sine qua nom, para a práxis pedagógica.

No que é referente ao desenvolvimento das questões tecnológicas, entende-se que a produção do pensamento é parte fundamental para se compreender as transformações dos processos educacionais. Segundo Silva e Carvalho (2012, p. 114):

A escola, ainda é o espaço fundamental de produção do conhecimento crítico, desde que a entendamos, também, como o lócus onde as problemáticas do contexto histórico e social se materializam. Por essa razão, ela explicita claramente esse espaço da crítica às contradições sociais.

Nesse sentido, a análise acerca da produção do manual didático é fundamental, até porque caracteriza um fato importante, segundo Alves (2008 p. 105), do problema do anacronismo existente no contexto escolar, fato que não transparece o problema da exclusão presente no contexto escolar.

O processo de formação dos professores, em nossos dias, só faz reiterar essa dissonância. Por continuarem reproduzindo a organização manufatureira do trabalho didático e, ao mesmo tempo, por induzirem à crença em uma autonomia do docente na direção do processo de formação de crianças e jovens, os cursos de formação e treinamento de professores produzem profissionais que realizam diuturnamente, também eles, uma prática que reforça a dissonância. Esses cursos são fundamentais, portanto, para manter a escola manufatureira tal como se encontra e, ao mesmo tempo, para cultivar o mito do professor que impõe direção autônoma ao trabalho didático. Em resumo, por aferrarem a escola ao passado e por resistirem à mudança, esses cursos de formação e treinamento de professores são politicamente reacionários.

Do ponto de vista da produção da ciência, a análise crítica acerca dos manuais é relevante, porque toca diretamente na questão dos temas transversais propostos para a discussão dos problemas escolares. No entanto, ao se falar em transversalidade: o que 
2 Ao mesmo tempo em que se constata o grande número de grupos de pesquisa centrados na temática formação de professores no Brasil, verifica-se que a produção do conhecimento basicamente reitera a forma de se fazer educação dentro das escolas. Assim sendo, contribui, sobretudo, para a reprodução da anacrônica organização do trabalho didático dominante e não para sua transformação (ALVES, 2008). significa discutir sobre a temática étnico-racial a partir deste viés, na medida em que a situação dos negros perpassa toda uma situação histórica carregada dos ranços de uma realidade patriarcal e excludente como a brasileira?

Assim, é importante mencionar que o manual didático tem uma função ideológica que se constitui desde sua constituição por Comenius; sua função era reproduzir os ideais da sociedade manufatureira, cujo objetivo estava em apropriar-se dos domínios da produção, porém manter a exclusão como questão precedente da realidade escolar ${ }^{2}$. Com efeito, a escola se tornou objeto de obrigatoriedade política; contudo, as Diferenças no processo das relações sociais, divergem quanto aos seus objetivos.

A produção dos manuais didáticos consubstanciam os fundamentos das teorias educacionais contemporâneas naquilo que propõem como base para a educação desse século. Isso significa afirmar que o viés ideológico presente no escopo dessas teorias é pertinente aos principais objetivos da agenda pós- moderna para educação. Desse modo, a discussão sobre a raça passa pela valorização das diferenças étnicas culturais; por sua vez, as formas de dominação dos sistemas produtivos e a imposição ideológica do embranquecimento sobre a condição dos negros e trabalhadores não transparecem na discussão proposta.

No campo das transformações dos sistemas de produção, descaracterizar a teoria como forma de empobrecimento das questões emergenciais da educação é base na qual estão assentados os discursos reformadores da agenda pós-moderna, cujo objetivo está em desviar o foco da análise para fatores desconexos com a problemática da educação. Nesse sentido, segundo Duarte (2008, p. 12):

Quando uma ilusão desempenha um papel na reprodução ideológica de uma sociedade, ela não deve ser tratada como algo inofensivo ou de pouca importância por aqueles que busquem a superação dessa sociedade. Ao contrário, é preciso compreender qual o papel desempenhado por uma ilusão na reprodução ideológica de uma formação societária específica, pois isso nos ajudará a criarmos formas de intervenção coletiva e organizada na lógica objetiva dessa formação societária. [...] E qual seria a função ideológica desempenhada na assim chamada sociedade do conhecimento? No meu entender, seria justamente a de enfraquecer a luta por uma revolução que leve a uma superação radical do capitalismo, gerando a crença de que essa luta teria sido superada pela preocupação com outras questões "mais atuais", tais como a questão da ética na política e na vida cotidiana pela defesa dos direitos do cidadão e do 
consumidor, pela consciência ecológica, pelo respeito às diferenças sexuais, étnicas ou de qualquer outra natureza.

É fato que a análise sobre a valorização das questões étnico-raciais é questão sine qua non, no entanto, como assevera Duarte (2008 p. 12), quando essa análise está desatrelada das questões reais da dominação burguesa, esse discurso se torna ilusório e visto apenas em sua superficialidade. Assim, o problema das diferenças não pode ser resolvido. Nesse sentido, apenas com as políticas de Ação-Compensatória, mas também com o trabalho vivo do professor que busca compreender quais os principais objetivos do que se projeta como ideal educativo para a sociedade brasileira.

Portanto, essa análise se coloca sobre essa dimensão de compreender os métodos e os processos da produção do manual didático para o debate acerca das relações étnicos-raciais e sua interface com as teorias educacionais contemporâneas, em especial a discussão da complexidade. A proposta será a de contribuir com o debate acerca da produção do pensamento pedagógico: seu estado da arte, no que se refere ao debate acerca do trabalho docente e com a crítica aos fundamentos que hoje se apresentam como transformadores da realidade educacional, mas que carrega, em sua essência, o problema ideológico das formas de dominação dos sistemas produtivos.

Com base na argumentação apresentada para a construção do corpus teórico dessa análise: na primeira parte, far-se-á a análise histórica da escola e sua estruturação, a base que compõem sua organização e sua relação na construção do material didático; na segunda parte, serão abordadas as propostas e as políticas educacionais para a diversidade e sua relação com as teorias contemporâneas da educação sobre os temas transversais que, se apresenta na interface com a realidade do ensino; na terceira parte a discussão girará em torno do material didático e sua composição e caracterização ideológica, além de suas representações, quando se constatará a hipótese levantada sobre a marginalização do negro na cultura brasileira e sua composição no imaginário social. Como questão conclusiva a proposta será a de apresentar os instrumentos que norteiam o debate político em sua confluência com o debate educacional, no qual estão presentes os processos de formação da cultura negra.

\section{ANÁLISE HISTÓRICA DA ORGANIZAÇÃO ESCOLAR E SUA RELAÇÃO COM A PRODUÇÃO DO MATERIAL DIDÁTICO}

A concepção da escola pública, laica, focada nos princípios da ciência e produção humanística, em suma os ideais modernos da educação, surgiu no final século XVIII e princípios do século XIX. Sua constituição estrutural e 
ideológica estava assentada aos ideais do iluminismo, cuja necessidade fora a de propagar os princípios pedagógicos da universalização do ensino. Esse processo partiu do princípio de organização da vida em sociedade, na medida em que as relações: econômicas, de trabalho e da constituição do "homem livre"; passavam por transformações circunstanciais no período em questão, devido à racionalização da produção e à organização da atividade produtiva. Com o advento da industrialização, a divisão do trabalho e as mudanças nas relações sociais tornaram-se os fatores essenciais das relações de produção. Desse modo, surgiu a demanda por um modelo de cidadão capaz de se adaptar às necessidades da classe que se estabelecia no poder, consolidando seus interesses: a classe burguesa.

A especialização do saber, segundo Alves (2006, p. 9), "[...] é a forma pela qual se realiza a divisão do trabalho no mundo do conhecimento, é o que condiciona a formulação dos conceitos acerca das relações nas diferentes ocupações tornando os eixos fixos". Ao analisarmos essa questão em termos escolares, é perceptível que a educação seria o instrumento impulsionador da sociedade, através de suas qualidades e virtudes, fato que guiaria o homem à sua maturidade e o desenvolvimento social e se realizaria sob a base da especialização.

Com o advento da manufatura e o processo de superação do artesanato, transparece a necessidade de uma nova força produtiva. Essa nova força é imanente à caracterização assumida pelo trabalhador, visto que, ao aumentar sua produtividade, resultou em um crescimento qualitativo fundando as bases da produção capitalista. Comenius (1976), um dos principais defensores da escola moderna, pensou sua organização fundada na estrutura da manufatura e não do artesanato. Para efeito de exemplo, o registro em sua obra maior, a didática magna: "[...] Na verdade, há uma grande economia de fadiga e de tempo, quando uma só pessoa faz uma só coisa, sem ser distraída por outras coisas; deste modo, com efeito, uma só pessoa pode servir utilmente a muitas, e muitas podem servir a uma só" (1976 apud ALVES, 2006, p. 73).

Sendo assim, Comenius almejou a organização da escola, equivalente à ordem da manufatura, de maneira que a divisão do trabalho possibilitasse diferentes operações, executadas por trabalhadores distintos. A escola se materializou na concepção do grupo escolar e da racionalização do processo pedagógico, cujo desenvolvimento se dava de maneira sistemática e controlada a partir de um plano prévio que se articulava, para obter um resultado com economia de tempo, de recursos e evitando a fadiga.

Essa empreitada foi impregnada pela "[...] clareza de que o estabelecimento escolar deveria ser entendido como uma oficina de homens; tendo em vista a convicção de que a escola deveria se estruturar tendo como parâmetro as artes" (ALVES, 2006, p. 72). A manufatura à época em que viveu Comenius, segundo Alves (2006, p. 73), era 
considerada pertencente ao campo das artes, fato responsável pelo desenvolvimento e propagação desse conceito. Este aspecto investira-se de uma acepção distinta que expressava ligação literal e histórica com o ofício medieval ou artesanato. Depois de ter se apropriado da base prática do artesanato, o sistema fabril representava a superação deste. Com a divisão do trabalho, desestruturou-se o ofício medieval em suas operações práticas, do mesmo modo como se especializou o artífice em determinadas operações, como também as ferramentas de seu trabalho, que ganharam funções mais adequadas às tarefas em que eram empregadas.

A ordenação de várias atividades em conjunto executadas por diferentes trabalhadores proporcionou à manufatura a evolução da produção e do trabalho. A linha de produção legitimou a formatação racional do trabalho na medida em que havia um determinado número de trabalhadores atuando no processo. Pelo processo de racionalização, constituiu-se a divisão do trabalho. Esta, por sua vez, consubstanciou o ideal de produção em larga escala, o excedente da produção, em detrimento do ideal artesanal da produção, focada nos princípios da cultura.

Constantes analogias confirmam a tentativa de ilustrar a aproximação da prática de ensino, tal como ele projetava, e os referenciais das atividades da arte.

15. A Arte de ensinar nada mais exige [...] que uma habilidosa repartição do tempo, das matérias e do método. Se a conseguirmos estabelecer com exatidão, não será nada difícil ensinar tudo à juventude escolar, por mais numerosa que ela seja, que imprimir, com letra elegantíssima, em máquina de Arquimedes, casas, torres ou qualquer outra espécie de pesos, ou atravessar num navio um oceano e atingir o novo mundo. E tudo andará com não menor prontidão que um relógio posto em movimento regular pelos seus pesos. E tão suave e agradavelmente como é suave e agradável o andamento de um tal autômato. E, finalmente, com tanta certeza quanta pode obter-se de qualquer instrumento semelhante, construído segundo as regras da arte.

16. Procuramos, portanto, em nome do Altíssimo, dar às escolas uma organização tal que corresponda, em todos os pontos, à de um relógio, construído segundo as regras da arte e elegantemente ornado de cinzeladuras variadas. (COMENIUS, 1976 apud ALVES, 2006, p. 73).

$\mathrm{Na}$ introdução de sua obra, Comenius buscou traduzir o significado de seu título e de seu subtítulo, de acordo com as especificações do empreendimento que a estruturava, com intenção de explicitar fins e objetivos visados, descrevendo os meios que deveriam 
fundar a "Escola para todos". Escola essa que se fundaria na base comum dos conhecimentos das coisas e verdades através de exemplos paralelos referentes às artes, buscando menos trevas mais luz e harmonia.

Didáctica [sic] Magna: tratado da arte universal de ensinar tudo a todos ou processo seguro e excelente de instruir, em todas as comunidades de qualquer reino cristão, cidades e aldeias, escolas tais que toda a juventude de um e de outro sexo, sem exceptuar [sic] ninguém em arte em parte alguma, possa ser formada nos estudos, educada nos bons costumes, impregnada de piedade, e, desta maneira, possa ser, nos anos de puberdade, instruída em tudo que diz respeito à vida presente e futura, com economia de tempo e fadiga, com agrado e solidez. Onde o fundamento de todas as coisas que se aconselham são tirados da própria natureza das coisas; a sua verdade é demonstrada com exemplos paralelos das artes mecânicas; o curso dos estudos é distribuído por anos, meses, dias e horas; e, enfim, é indicado um caminho fácil e seguro de pôr todas as coisas em prática com bom resultado. A proa e a popa da nossa didáctica [sic] será investigar e descobrir o método seguro o qual os professores ensinem menos e os estudantes aprendam mais; nas escolas, haja menos barulho, menos enfado, menos trabalho inútil, e, ao contrário, haja mais recolhimento, mais atractivo [sic] e mais sólido progresso; na cristandade haja menos trevas, menos confusão, menos dissídios, e mais luz, mais ordem, mais paz e mais tranquilidade. (COMENIUS, 1976 apud ALVES, 2006, p. 74).

Ao desenvolver essas metas, o educador deveria procurar um modo por meio do qual a escola fosse colocada em funcionamento. Para tanto, existiam entraves, falta de pessoal especializado na prática, capaz de gerar "sólidos frutos", e os condicionamentos econômicos que poderiam tornar-se responsável pela não expansão da escola (ALVES, 2006). Tal consciência não se revela de maneira indireta, somente quando se afirma a necessidade de a escola ofertar serviços que garantam economia de tempo e de fadiga. Outros tipos de fatores já passavam despercebidos aos estudiosos da obra de Comenius ou a elas não têm se dado a devida atenção.

5. No entanto, mesmo que houvesse professores assim competentes, que aprendessem facilmente a desempenhar as suas funções em conformidade com os nossos planos, como seria possível remunerá-los convenientemente, se tivessem de fixar-se em todas as cidades, em todas as aldeias e em todos os lugares onde nascem e se educam homens de cristo? 
6. E, além disso, com que subsídios poderiam ajudar-se os filhos dos mais pobres que frequentam a escola? (COMENIUS, 1976 apud ALVES, 2006, p. 75).

Logo, as perspectivas desenvolvidas por Comenius já se materializavam em sua obra, na qual reconhecia o elevado custo das escolas. Daí a existência de implementos econômicos de seleção da clientela.

7. [...] onde existem [escolas], não são indistintamente para todos, mas apenas para alguns, ou seja, para os ricos, porque, sendo dispendiosas, nelas não são admitidos os mais pobres, salvos casos raros, ou seja, quando alguém faz uma obra de misericórdia. (COMENIUS, 1976 apud ALVES, 2006, p. 75).

Quando inserido o debate na esfera econômica, Alves (2006) aponta outro aspecto à obra de Comenius, isto é, o caráter religioso e civil que tornavam majestosa a expansão da escola para todos, possibilidade essa que residia no barateamento de seus custos. Tal solução se dá através da transformação do instrumental do trabalho didático.

O material didático surgiu com a pretensão de consubstanciar uma síntese dos conhecimentos humanos de forma mais adequada ao desenvolvimento e à assimilação da criança e do jovem. Especializou-se, também, em função dos níveis de escolarização e das áreas de conhecimento, multiplicando-se da mesma forma que os instrumentos de trabalho, dentro da oficina, que, por força da divisão do trabalho, ganharam as configurações mais adequadas às operações que realizavam. (ALVES, 2006, p. 76).

3 Derivação: por extensão de sentido. Rubrica: filosofia. No marxismo, o processo por meio do qual o trabalho humano, transformado a natureza circundante, é materializado em objetos, o que pode ser empreendido conscientemente, no comunismo, ou de forma alienada, no capitalismo e nas sociedades pregressas.

$$
\text { (ALVES, 2006, p. 76). }
$$

A partir de então, o material didático passou a prestar uso integral ao aluno e ao professor, dotado de autossuficiência enquanto aparato organizador do trabalho de ensino ao excluir da escola as obras clássicas. Com efeito, o que aconteceu nesse processo legitimou o ideal de simplificação e objetivação ${ }^{3}$ do trabalho didático, uma vez que o manual proporcionou a diminuição dos valores da instrução pública. Isso correspondeu a uma predeterminação básica à universalização do ensino. A escola, por sua vez, apontaria para um desenvolvimento do conhecimento humano como forma de organização social, sendo o trabalho realizado pelo intermédio de suas ferramentas. Deste modo, e atendendo à lógica do processo simples de trabalho, estruturou-se um material com conteúdo de fácil assimilação, em determinado sentido banal e direcionado. 
distintas áreas do conhecimento, estreitou os limites do saber exigido do professor, pois, objetivamente, registrou-os aos próprios limites. Assim, concretizou de uma forma evidente, também, a reprodução da divisão do trabalho, dentro do estabelecimento escolar, de um modo similar ao ocorrido anteriormente na manufatura. (ALVES, 2006, p. 88).

O caráter ideológico no manual didático manifesta-se através da lógica manufatureira; tendo a escola incorporado o processo de organização da manufatura que, estruturou sua base na divisão do trabalho, o material didático tornou-se reprodutor de um perfil apto ao mercado. Perfil esse que partilha das noções matemáticas primárias como: adição, subtração, divisão e multiplicação. O mesmo se aplica à escrita e à leitura. E, na sua modalidade mais simples, a no manual didático atenderia diretamente às suas necessidades nas relações de trabalho e sociedade, prioridade essas atribuídas sobre a Educação Básica. Para exemplificar as questões apresentadas anteriormente, podemos citar aqui a proposta do Banco Mundial sobre os fundamentos norteadores da educação mundial:

A educação é a pedra angular do crescimento econômico e desenvolvimento social e um dos principais meios e para melhorar o bem-estar dos indivíduos. Ela aumenta a capacidade produtiva das sociedades e suas instituições políticas, econômicas e científicas e contribui para diminuir a pobreza, acrescentando o valor e a eficiência ao trabalho dos pobres e mitigados, as consequências da pobreza nas questões vinculadas à população, saúde e nutrição [...] o ensino de primeiro grau é a base e sua finalidade fundamental é dupla: produzir uma população alfabetizada que possua conhecimentos básicos de aritmética capaz de resolver problemas no lar e no trabalho, e servir de base para sua posterior educação. (BANCO MUNDIAL 1992 apud TOMMÁSI, 1996, p. 131).

Na concepção descrita sobre a educação mundial, é perceptível a articulação do conteúdo básico de ensino, como item principal nas relações de sociedade e trabalho. Nesse sentido, a Educação Básica é o eixo norteador do modelo de sociedade que se deseja formar, e o manual didático seria o instrumento de formação desse perfil. Ao professor, que confere sua prática apoiada no manual didático, cabe executar o conteúdo proposto com base nos Parâmetros Curriculares Nacionais (PCNs) e no Plano Político-Pedagógico (PPP) de cada escola, tornando-se reprodutor de um conteúdo cuja concepção, bem como seu planejamento, sua organização e seu controle ficam destinados a especialistas supostamente capacitados.

O manual didático situa-se, portanto, em um patamar superior ao professor, predeterminando o conteúdo 
4 A Lei $n^{0}$ 9.394/96 Lei de Diretrizes e Bases da Educação (LDB) faz saber, através do título II Dos Princípios e Fins da Educação Nacional: Art. $2^{\circ}$. A educação, dever da família e do Estado, inspirada nos princípios de liberdade e nos ideais de solidariedade humana, tem por finalidade o pleno desenvolvimento do educando, seu preparo para o exercício da cidadania e sua qualificação para o trabalho (BRASIL, 1996). de suas práticas; o que se deve trabalhar e como trabalhar, reproduzindo o discurso marginalizante e excludente da escola. A escola aqui é entendida como palco de atuação de professores e alunos, atores no processo de formação, cada qual desempenhando seu papel.

\subsection{O espaço escolar e sua configuração nas relações sociais}

Sendo a escola um espaço de convívio e sociabilidade esta se torna o lócus pelo qual é propagada a ideologia de determinado sistema econômico e, portanto, que influencia no processo de formação dos indivíduos. ${ }^{4}$ Desse modo, é função da escola ensinar os valores e incorporar os princípios que tangenciam a moral e a ética que regulam o contexto social. Os valores trabalhados na escola, se nos atermos às questões ideológicas que determinam as relações econômicas, podem exercer uma relação de força que pode ser entendida como violência simbólica que se dá entre grupo ou classes. Desse modo, de acordo com Saviani (2000, p. 18), entende-se que:

[...] "toda e qualquer sociedade estrutura-se como um sistema de relações de força material entre grupos ou classes". Sobre a base da força material e sob sua determinação erige-se um sistema de relações de força simbólica cujo papel e reforçar, por dissimulação, as relações de força material.

A violência simbólica, cuja ideologia está subscrita à concepção das teorias reprodutivitas, na escola se efetiva pela força de grupos ou classes que, por carga do capital social e econômico superior ao dos grupos oprimidos ou dominados que circulam no espaço público da escola, impõem uma relação força como legítima é opressora.

Todo poder de violência simbólica, isto é, todo poder que chega a impor significações e a impô-las como legítimas, dissimulado as relações de força que estão na base de sua força, acrescenta sua própria força, isto é, propriamente simbólica, a essas relações de força. (Bourdieu 1975 apud SAVIANI, 2000, p. 18).

Portanto, segundo Saviani (2000, p. 20), em uma crítica à concepção de Bourdieu e Passeron, "[...] a teoria não deixa dúvidas, a função da educação é a de reprodução das desigualdades sociais. Pela reprodução cultural, ela contribui especificamente para a produção social". Isto é, para os grupos ou as classes sociais desfavorecidos socialmente, a escola deveria ser o lócus onde o contato com a cultura historicamente produzida aconteceria. No entanto, o que se percebe 
desse contexto é justamente o contrário, o problema da escola brasileira perpassa o problema histórico de sua constituição, isso significa afirmar que há um hiato entre as condições materiais e culturais desses segmentos em relação à escola. Tal perspectiva se mostra por intermédio do poder da ideologia que perpassa os muros escolares e se materializa na ação pedagógica institucionalizada.

O sistema de relação de força dentro da escola, materializado pela ideologia, se traduz em imposição dos valores incorporados nas relações sociais. Esses valores se caracterizam pela produção da marginalidade daqueles que não participam efetivamente da superestrutura do capital. Isso implica considerar que o sistema de competitividade que passa a existir no contexto escolar; as relações de interação entre os indivíduos também obedecem a essa ordem, de maneira que a imposição da força material ocorre pela afirmação dos grupos dominantes. Traduzindo sua força em propriedade: aquele que não a possui está excluído automaticamente do contexto social. E essa imposição se traduz desse modo:

Marginalizados são os grupos ou classes dominados. Marginalizados socialmente porque não possuem força material (capital econômico) e marginalizados culturalmente porque não possuem força simbólica (capital cultural). E a educação, longe de ser um fator de superação da marginalidade, constitui um elemento reforçador da mesma. Eis a função logicamente necessária da educação. Não há outra alternativa. Toda tentativa de utilizá-la como instrumento de superação da marginalidade não é apenas uma ilusão. É a forma através da qual ela dissimula e, por isso, eficazmente sua função de marginalização. Todos os esforços, ainda que oriundos dos grupos ou classes dominados, reverte sempre no reforçamento dos interesses dominantes. (SAVIANI, 2000, p. 21).

Sobre tal aspecto, a escola reproduz a ideologia dominante do Estado, que se caracteriza pela materialidade das relações de ordem capitalista, relações essas que moldam os valores sociais e reconhecem o indivíduo como integrante desse sistema. Ou seja, o sujeito somente é reconhecido na sociedade pelo poder de consumo que se converte em posse material; que se constitui como valor intrínseco na formação escolar.

A escola constitui o instrumento mais acabado de reprodução das relações de produção de tipo capitalista. Para isso, ela toma a si todas as crianças de todas as classes sociais e lhes inculca durante anos a fio de audiência obrigatória "saberes práticos" envolvidos na ideologia dominante. (ALTHUSSER [s. d.] apud SAVIANI, 2000, p. 23). 
A escola, nesse sentido, defende os interesses das classes dominantes, configurando-se como aparelho de manutenção de domínio, desenvolvendo sempre que necessário os mecanismos de adequação que impedem a sua transformação; isto é, a educação é considerada como fator determinante na formação do tipo de sociedade que corresponde a esses interesses. Cabe agora observar como essas questões interferem na construção dos materiais didáticos.

\subsection{As representações sociais ideológicas no Material Didático}

De acordo com os PCNs: "Se" existem diferenças socioculturais marcantes, que prezam por diferentes necessidades de aprendizagem, existe também o que é de comum acesso a todos, que um aluno de qualquer lugar do país deve ter acesso ao conhecimento e educação, direito esse que deve ser garantido pelo Estado na distribuição de material didático nas redes públicas de ensino. O conteúdo ideológico no discurso homogênico do material didático não leva em consideração o contexto individual de cada ser humano, colocando em esfera máxima toda sociedade, sendo uma estrutura igualitária. Saviani (2000, p. 4) aponta que:

[...] o que respeita a relação entre educação e sociedade, concebe-se a educação com uma ampla margem de autonomia em face da sociedade. Tanto que lhe cabe um papel decisivo na conformação da sociedade, evitando sua desagregação e, mais do que isso, garantindo a construção de uma sociedade igualitária.

A educação é vista como um bem comum a todos; item básico de direto supostamente garantido pelo Estado, que deveria garantir e zelar por educação de qualidade cujo objetivo deveria ser o de fiscalizar e fazer cumprir esse direito.

Sendo a escola um direito, o material didático é por excelência a ferramenta prática dos professores que: domina e embasa o trabalho docente; além de conter certo grau de conhecimento relativo ao que deve ser assimilado pelo aluno. Nesse sentido, a função do material didático é a de suprir as necessidades do trabalho pedagógico, da deficiência e da formação docente para o exercício da profissão.

O livro didático tem como disposição prévia perpetuar e inculcar conhecimentos sistematizados a serem desenvolvidos no plano de cada disciplina do currículo. Não apenas sumariza conteúdos, como reflete tendências de como a elite intelectual acredita que a educação deve ser guiada no processo escolar, assim como o modelo de sociedade por esta projetada. 
Segundo Costa (2007, p. 28), o livro didático: [...] "É o instrumento que vem, historicamente, no que se refere aos conteúdos específicos, subsidiando o processo educativo; mas, ao mesmo tempo, servindo de suporte à construção do imaginário nacional [...]”. O livro didático se torna, na maioria das vezes, a única fonte de pesquisa para o aluno. Do ponto de vista das relações pedagógicas, o livro didático assume a característica de amparo para reflexões e questionamentos. Por outro lado, é contraditório pensar que o referencial didático proposto no livro seja encarado com neutralidade. Devido à sua ideologia e à manutenção dos processos dominadores da produção, esse referencial coaduna os valores de um ideal educativo que será estudado pelos alunos ao longo dos anos de sua formação. Desse modo, Segundo Costa (2007, p. 30):

O que são as palavras postas em um livro? O que esses símbolos mortos? Nada, absolutamente. O que é um livro se não abrimos? É simplesmente um cubo de papel e couro, com folhas; mas, se o lemos, acontece algo estranho. Creio que muda a cada vez.

Mesmo se caracterizando como veículo difusor de ideologia, também possui a capacidade de auxiliar o professor a aperfeiçoar, no trabalho constante, a superar práticas impróprias. Estrutura-se como fenômeno de massa, capaz de atingir os mais diversos setores sociais e a visão dos grupos que retêm o domínio intelectual perante a sociedade, pela representação de maneira verbal e não verbal ou ambas em conjunto. Sobre um discurso de igualdade e democracia, cidadania que se consolida na prática social.

\section{O ESTADO DA ARTE SOBRE A CONDIÇÃO DO NEGRO NOS MATERIAIS DIDÁTICOS DA EDUCAÇÃO INFANTIL}

Os manuais pesquisados e reunidos para análise apresentaram uma variedade de concepções sobre a temática "cultural africana e afrodescendente" dentro do que prevê a Lei n ${ }^{0}$ 10.639/2003, que torna obrigatório o ensino de História e Cultura Africana e Afro-brasileira em todas as escolas públicas e particulares, do Ensino Fundamental e Ensino Médio. Com base nos dados coletados nos manuais analisados, percebemos claramente que os mesmos ainda reproduzem e contribuem com vários elementos para manutenção do imaginário social sobre a história do negro no Brasil; elementos esses que caracterizam uma identidade marcada por apenas uma perspectiva histórica dentro do processo de colonização. O negro ainda continua representado como o eixo secundário na escala de valores humanos, sendo entendido como alguém que deve ser integrado em um sistema vigente que não considera os valores de sua formação humana. 
Para o desenvolvimento da análise, buscou-se trabalhar com quatro categorias de análise que serão aplicadas ao nível de aprofundamento das questões apresentadas no material didático, são elas: Categoria 1 - representação do negro; Categoria 2 - fundamentação da cultura africana; Categoria 3 - questões ideológicas da cultura; Categoria 4 - não representação.

Quadro 1 - Dados da pesquisa

\begin{tabular}{|c|c|c|c|c|}
\hline Livro & Categoria 1 & Categoria 2 & Categoria 3 & Categoria 4 \\
\hline $\begin{array}{l}\text { História Projeto Buriti: história. } \\
\text { Ed. Moderna }\left(2^{\circ} \text { Ano }\right)\end{array}$ & - & - & - & $100 \%$ \\
\hline $\begin{array}{l}\text { História Projeto Buriti: história. } \\
\text { Ed. Moderna }\left(3^{\circ} \text { Ano }\right)\end{array}$ & $30 \%$ & $30 \%$ & $70 \%$ & - \\
\hline $\begin{array}{l}\text { História Projeto Buriti: história. } \\
\text { Ed. Moderna }\left(4^{\circ} \text { e } 5^{\circ} \text { Ano }\right)\end{array}$ & $40 \%$ & $40 \%$ & $80 \%$ & - \\
\hline $\begin{array}{l}\text { Coleção plural: Letramento e Alfabetização. Saraiva }\left(2^{\circ} \text { Ano) }\right. \\
\text { Suplemento do Professor }\end{array}$ & $50 \%$ & $50 \%$ & - & - \\
\hline $\begin{array}{l}\text { Coleção plural: Letramento e Alfabetização. Saraiva ( } 3^{\circ} \text { Ano) } \\
\text { Suplemento do Professor }\end{array}$ & $50 \%$ & $50 \%$ & - & - \\
\hline $\begin{array}{l}\text { Coleção plural: Letramento e Alfabetização. Saraiva ( } 4^{\circ} \text { Ano) } \\
\text { Suplemento do Professor }\end{array}$ & $50 \%$ & $50 \%$ & - & - \\
\hline $\begin{array}{l}\text { Coleção Porta Aberta: história. } \\
\text { FTD }\left(2^{\circ} \text { Ano }\right)\end{array}$ & $20 \%$ & $10 \%$ & $5 \%$ & \\
\hline $\begin{array}{l}\text { Coleção Porta Aberta: história. } \\
\text { FTD }\left(3^{\circ} \text { Ano }\right)\end{array}$ & $50 \%$ & $30 \%$ & $50 \%$ & \\
\hline Coleção Porta Aberta: Letramento e Alfabetização. FTD. & $20 \%$ & $10 \%$ & $5 \%$ & \\
\hline $\begin{array}{l}\text { Tudo da Trama - Tudo dá Trama. Enunciação e Gramática. Ed. } \\
\text { Dimensão. }\end{array}$ & $20 \%$ & $20 \%$ & $35 \%$ & $20 \%$ \\
\hline $\begin{array}{l}\text { Coleção Língua e Literatura. } \\
\text { Ed. Âtica. }\end{array}$ & $24 \%$ & $44 \%$ & $18 \%$ & $28 \%$ \\
\hline $\begin{array}{l}\text { Coleção Português: linguagens. } \\
\text { Ed. Saraiva (6 } 6^{\circ} \text { Ano). }\end{array}$ & $44 \%$ & $25 \%$ & $35 \%$ & $45 \%$ \\
\hline $\begin{array}{l}\text { Coleção Conexões com a História. } \\
\text { Ed. Moderna (E. M.). }\end{array}$ & $24 \%$ & $44 \%$ & $16 \%$ & $28 \%$ \\
\hline
\end{tabular}

Na perspectiva proposta, foram analisados os seguintes manuais do Ensino Fundamental presente na realidade das escolas de Mariana/MG:

1. THAHIRA Rosane C. História. Projeto Buriti: história. 2. ed. São Paulo: Ed. Moderna, 2011. 4 v. [para alunos] (Coleção).

2. MARINHO, Luiza F.; BRANCO, Maria da Graça. Coleção plural: Letramento e alfabetização, $2^{\circ}$ ano. 1 . ed. São Paulo: Saraiva, 2011. (Coleção).

3. LIMA, Mirna. Porta Aberta: história: $2^{\circ}$ ano. 1. ed. São Paulo: FTD, 2011.

4. CARPANEDA, Isabella Pessoa de M.; BRAGANÇA, Angiolina Domanico. Porta Aberta: Letramento e Alfabetização, $3^{\circ}$ ano. 1. ed. São Paulo: FTD, 2011.

5. LARA, Anésia; LOPES, Vera. Tudo da Trama Tudo dá Trama. Enunciação e Gramática a serviço do texto. Belo Horizonte: Editora Dimensão, 1997. 4 v.

6. FARACO \& MOURA. Língua e Literatura. Editora Ática. 
7. CEREJA, William R.; MAGAlHÃES, Thereza C. Português: linguagens, $6^{\circ}$ ano: língua portuguesa. 7 . ed. reform. São Paulo: Saraiva, 2012.

8. ALVES, Alexandre; OLIVEIRA, Letícia F. de. Conexões com a História. São Paulo: Ed. Moderna, 2010. A partir dos materiais, no quadro a seguir destacamos como o fenômeno da questão étnico-racial está presente nos manais.

\subsection{Osaspectos Ideológicos doMaterial Didático e sua interlocução com as teorias vigentes no discurso educacional: o que os dados revelam, sobre os fundamentos propostos na pesquisa?}

Para os eixos estruturais desta análise, cuja discussão se assenta na questão epistemológica da educação, é necessário compreender os seus impactos na realidade escolar. Isto é, como as teorias educacionais, imbuídas pela perspectiva do material didático, são absorvidas na escola, de modo especial nas escolas periféricas? Quais os seus impactos na formação da consciência dos jovens quanto à sua condição histórico- social? Como essas teorias influenciam na produção do pensamento dos jovens que se encontram marginalizados do processo social na realidade Mariana.

Os dados da pesquisa revelam que o material didático ainda se faz presente nas escolas como ferramenta de manutenção ideológica, principalmente nas escolas periféricas, ou seja, embora a cultura africana esteja presente em quase todos os materiais - excetuando o manual do $2^{\circ}$ ano do Projeto Buriti cuja representação não está presente -, o caráter ideológico dessa representação ainda perpetua nossas desigualdades sociais pela divisão de classes pelo acesso à educação, cristalizando as relações de poder já impostas pelas demandas sociais das classes mais abastadas. A história do negro se configura pelo processo escravista da tradição colonial brasileira. Deste modo, fica evidente que a visão ideológica de construção social mantém os ricos no topo da pirâmide e o pobre sustentando sua base.

Em que pesem os esforços para que conquistas fossem garantidas no âmbito legal, a realidade não se mostra tão promissora para as crianças brasileiras, em especial as crianças negras. De acordo com dados da Unicef, a média nacional de $38,6 \%$ fora da escola esconde iniquidade: entre as crianças brancas, o dado é mais favorável $(36,1 \%)$; entre as crianças negras, porém, $41 \%$ não frequentam a pré-escola. Essa disparidade demonstra a desigualdade entre brancos e negros desde o início da escolaridade. (BRASIL, 2006, p. 37).

Omaterial didático analisado reproduzumapagamento velado das questões históricas pertinentes à valorização da civilização africana, ora sobre uma visão romantizada, 
ora sobre um aspecto de submissão sobre o processo de inclusão excludente, ou seja, promove uma falsa inclusão social no grupo que se deseja fazer parte por imposição de demandas estabelecidas; mas, deixando bem clara qual é sua função e representatividade dentro desse meio. Uma vez incluso dentro do grupo, fica relegado ao indivíduo negro cumprir um papel secundário dentro das relações humanas, aceitando sua condição de inferior, com uma falsa perspectiva de ascensão e aceitação igualitárias dentro do grupo.

O silêncio da escola sobre as dinâmicas das relações raciais tem permitido que seja transmitida aos(as) alunos(as) uma pretensa superioridade branca, sem que haja questionamento desse problema por parte dos(as) profissionais da educação e envolvendo o cotidiano escolar em práticas prejudiciais ao grupo negro. Silenciar-se diante do problema não apaga magicamente as diferenças, $\mathrm{e}$ ao contrário, permite que cada um construa, a seu modo, um entendimento muitas vezes esteriotipado do outro que lhe é diferente. Esse entendimento acaba sendo pautado pelas vivências sócias de modo acrítico, conformando a divisão e a hierarquização raciais. (BRASIL, 2006, p. 23).

A condição de vida dos jovens das periferias de Mariana está subordinada à segregação, marginalização, falta de perspectivas ligadas à ascensão econômica e educacional, devido ao assentamento familiar, o qual está relacionado diretamente a uma linhagem humilde e sem esperança de vir a ocupar um lugar de destaque na sociedade em que vivem. Desse modo, depositam suas esperanças nas possibilidades de trabalho iminente, de fazerem parte do corpo de funcionários de alguma multinacional da mineração.

Desse modo, esses jovens acreditam que um emprego com um salário razoável irá atender a suas demandas existenciais. O jovem morador de periferia de Mariana se torna atrelado às necessidades básicas de sobrevivência e, por não ter condição financeira de se manter em um processo de ensino contínuo, opta por ingressar o mais precocemente no mercado de trabalho para ajudar no sustento da família e atender a suas necessidades econômicas emergências, perpetuando o estigma das relações de exploração capitalista. Tal fenômeno se manifesta nas relações de produção capitalista. O segundo Saviani (2000), a marginalidade na vida do jovem de periferia de Mariana se manifesta da seguinte forma:

Como interpretar, nesse quadro, o fenômeno da marginalidade? De acordo com essa teoria, marginalizados são os grupos ou classes dominados. Marginalizados socialmente porque não possuem força material (capital econômico) e marginalizados culturalmente, 
porque não possuem força simbólica (capital cultural). E a educação, longe de ser um fator de superação da marginalidade, constitui um elemento reforçador da mesma. Eis a função logicamente necessária da educação. Não há outra alternativa. Toda tentativa de utilizá-la como instrumento de superação da marginalidade não é apenas uma ilusão. É a forma através da qual ela dissimula e, por isso, cumpre eficazmente a sua função de marginalização. Todos os esforços, ainda que oriundos dos grupos ou classes dominados, reverte sempre no reforçamento dos interesses dominantes. (SAVIANI, 2000, p. 21).

Os dados revelam a condição do discurso ideológico no material didático, não só promovem um apagamento material e histórico do negro em nossa sociedade, como direcionam a realidade do negro a uma eterna condição de negação.

A discriminação vivenciada cotidianamente compromete a socialização e interação tanto das crianças negras quanto das brancas, mas produz desigualdade para as crianças negras, à média que interfere nos seus processos de constituição de identidade, de socialização e aprendizagem. (BRASIL, 2006, p. 38).

O discurso presente no material didático é de evidenciação da presença do negro nas relações, mas uma presença marcada pela condição histórica atrelada ao imaginário social onde a inclusão fica clara, mas sobre uma condição de coisificação relegada a um papel secundário como agente histórico na construção de nossa identidade nacional.

Por não ser considerado como agente fundamental na construção da identidade nacional o negro se torna invisível dentro dos espaços de interação, principalmente nos ambientes educativos, deixando de representar a grande maioria da população brasileira. Por não ter sua imagem refletida como importante e participativa no desenvolvimento do país o negro não aparece em destaque exercendo cargos e profissões de prestígio, tais como: médico, advogado, político e engenheiro, o que determina à população negra o não reconhecimento como pertencente à sociedade em que vive, gerando um sentimento de exclusão e não aceitação de si mesma. O negro passa a ser visto não simplesmente como o outro com quem devo conviver socialmente, mas como o "último outro" (RAHIER, 2001 apud COSTA, 2007, p. 36).

Devido à naturalização de tais contingências no livro didático, a história do negro e a cultura afro-brasileira se tornam superficiais, não cumprindo de fato o que pregam as políticas públicas e as teorias educacionais na conscientização das relações étnico-raciais na formação dos alunos para diversidade presente. Dessa forma, negando direitos de reconhecimento histórico humano, impossibilitando a 
releitura da condição social do negro. Isto é, mantendo o sujeito oprimido, inferiorizado, marginalizado e estigmatizado dentro de sua própria realidade como fato dado.

O que mais chama a atenção nas políticas públicas para educação é o fato de pregarem uma sociedade consciente de suas ações, no exercício democrático de seu direito, que dissimuladamente prega a igualdade, a tolerância e o respeito à diversidade cultural, sobre a falsa ideia de se tratar apenas de problema social. Mesmo se tratando de um discurso da cidadania com igualdade de direitos, constata-se, em linguagem verbal e não verbal, a construção de sentido pejorativo para o negro, mantendo a inferioridade e o desrespeito à sua dignidade, principalmente no tocante às diferenças culturais, raciais e religiosas, sempre como objeto de riso e intolerância.

Tendo em vista a caracterização ideológica do material didático referente à representatividade do negro e cultura afro-brasileira e africana, este material se torna uma ferramenta de reprodução do racismo, desigualdades, intolerância religiosa e cultural; o que se reflete na formação do aluno negro, resultando no seu direcionamento para o mercado de trabalho e não na continuidade da sua formação intelectual, sendo desencorajado pelo processo de ensino. Realidade que reflete na baixa porcentagem da população negra que continua no sistema educacional. Questão que entendemos apresentar o processo pedagógico da atividade didática presente no contexto dos manuais didáticos e a realidade dos sujeitos. De certo modo, a concepção de homem e de mundo presente no material didático não compreende a realidade dos seres vividos; como vimos, essa questão é ainda mais complicada quando tratamos da condição dos negros nesse contexto.

Os dados coletados e analisados no Quadro 1 apontam um grande nível de descaracterização dos valores históricos, há uma relatividade do tema com as teorias educacionais (manifestação ideológica) e fundamentação dos ideais de diversidade exigidos pelos PCNs, mas o não aprofundamento e a falta de crítica sobre a problemática real presente nas relações étnico raciais, demonstram que as teorias educacionais contemporâneas negligenciam as demandas obrigatórias da Lei $\mathrm{n}^{0} 10.639 / 2003$, há uma real e aparente dissimulação dos fundamentos da lei, visto que ela se faz vigorar na maioria dos manuais analisados, mas de maneira banal e distorcida, chegando a estupidez em determinados casos na representação de questões fundamentais.

\section{CONSIDERAÇÕES FINAIS}

De acordo com nos dados obtidos pela pesquisa pudemos constatar que a escola, desde sua origem, carrega perspectivas ideológicas com sua essência estruturada nas bases da manufatura, desde sua fundamentação teórica e política. A escola surge para atender à demanda do Estado 
e da classe Burguesa que se consolidava como grupo empresarial da época, para criação e estruturação da mão de obra para as atividades de trabalho em fábrica que, a partir do advento da industrialização, transformariam as relações de trabalho.

Por obedecer às relações de manufatura, a escola se baseou na organização e na divisão do trabalho para o desenvolvimento de seus objetivos, universalizar a escrita e leitura na capacitação do corpo de funcionários na utilização do maquinário que se implantava nas linhas de produção fabril. Dessa maneira, a escola se tornou pública e gratuita devido à proposta educativa ministrada em seu interior. Tal situação apenas se tornou possível depois de inúmeras transformações na sua gestão política e operacional, com a criação e capacitação do professor que se torna um dos principais agentes nesse processo e com o barateamento de custos e gastos. Tais manobras foram adequando à escola a realidade proposta.

Tendo em vista essa caracterização, o material didático se tornou uma ferramenta de reprodução das práticas manufatureiras, refletida na formação do aluno que obtém como resultado seu direcionamento para o mercado de trabalho e não a continuidade da sua formação intelectual. Entendemos que isso reflete o processo pedagógico da atividade didática presente no contexto dos manuais didáticos e a realidade dos sujeitos. De certo modo, a concepção de homem e de mundo presentes no material didático não compreende a realidade dos seres vividos; essa questão é ainda mais complicada quando tratamos da condição dos negros nesse contexto.

\section{REFERÊNCIAS}

ALVES, Gilberto Luiz. O trabalho didático na escola moderna: formas históricas. Campinas: Autores Associados, 2005.

ALVES, Gilberto Luiz. A produção da escola pública contemporânea. 4. ed. Campinas: Autores Associados, 2006.

ALVES, Gilberto Luiz. FORMAÇÃo DE PROFESSORES: UMA NECESSIDADE DE NOSSO TEMPO? 2008. Disponível em: <http://www.histedbr.fae.unicamp.br/revista/edicoes/31/arto8_31.pdf>. Acesso em: 14 nov. 2016.

ASSMANN, Hugo. Metáforas novas para reencantar a Educação; epistemologia e didática. 2. ed. Piracicaba: Editora Unimep, 1998.

BASBAUM, Leôncio. Alienação e Humanismo. São Paulo: Ed. Símbolo, 1977.

BAUMAN, Zygmunt. Globalização: As consequências humanas. Rio de janeiro: Jorge Zahar Ed, 1999. 
BRASIL. Lei $\mathrm{n}^{0}$ 9.394, de 20 de dezembro de 1996. Estabelece as diretrizes e bases da educação nacional. Diário Oficial da República Federativa do Brasil, Brasília, DF, 23 dez. 1996. Disponível em: <http://www.planalto.gov.br/ccivil_03/_Ato2011-2014/2014/Lei/L13005. htm>. Acesso em: 13 jan. 2014.

BRASIL. Ministério da Educação. Secretaria de Educação Fundamental. Parâmetros Curriculares Nacionais: Apresentação dos Temas Transversais Ética. Brasília: MEC/SEF, 1997. Disponível em: <http://portal.mec.gov. $\mathrm{br} / \mathrm{seb} /$ arquivos/pdf/livroo81.pdf $>$. Acesso em: 14 nov. 2016.

BRASIL. Ministério da Educação (MEC). Orientações e Ações para a Educação das Relações Étnico-Raciais. 2006. Disponível em: <http://portal.mec.gov.br/ dmdocuments/orientacoes_etnicoraciais.pdf $>$. Acesso em: 14 nov. 2016.

BRASIL, Ministério da Educação (MEC). Plano Nacional de Implementação das Diretrizes Curriculares Nacionais para Educação das Relações Etnicorraciais e para o Ensino de História e Cultura Afrobrasileira e Africana. portal.mec.gov.br/index. php?option=com_docman\&task...

CAVALLEIRO, Eliane dos Santos (Org.). Racismo e anti-racismo na educação: repensando nossa escola. São Paulo: Summus, 2001.

COSTA, Candida Soares da. O negro no livro didático de língua portuguesa: imagens e percepções de alunos e professores. Cuiabá: UFMT/IE, 2007.

DELORS, Jacques. (Org.). Educação Um Tesouro a Descobrir: Relatório para a UNESCO da comissão internacional sobre a educação para o século XXI. 8. ed. São Paulo: Ed. Cortez; Brasília: MEC; UNESCO, 2003.

DUARTE, Newton. Sociedade do Conhecimento ou Sociedade das Ilusões? Campinas: Autores Associados, 2008. (Coleção Polêmicas do Nosso Tempo).

ENGELS, Friedrich. A situação da classe trabalhadora na Inglaterra; São Paulo, Boitempo, 2008. (mundo estranho; coleção Marx - Engels).

GODOI, Guilherme C. de Souza. O Recorte Étnico-Racial na Cobertura Social Brasileira: uma ausência flagrante. Disponível em: http://www.usp.br/nce/wcp/arq/ recoedeetnicoracial_4texto.pdf $>$. Acesso em: 14 nov. 2016.

KOSIK (2002). 
LOBATO, Monteiro. O Presidente Negro ou o Choque das Raças: Romance Americano do ano 2228. São Paulo: Clube do Livro, 1945.

LOPES, Eliane Marta Teixeira. As Origens da Educação Pública: A Instrução na Revolução Burguesa do Século XVIII. Belo Horizonte: Argvmentvm, 2008.

MEDEIROS, Maria Neves de. A educação de jovens e adultos como expressão da educação popular: a contribuição do pensamento de Paulo Freire. In: COLÓQUIO INTERNACIONAL PAULO FREIRE, 5., 19-22 set. 2005, Recife. Anais... Recife: ?, 2005. Disponível em: <http:// www.paulofreire.org.br/pdf/comunicacoes_orais/A\%20 EDUCA\%C3\%87\% $3 \% 83$ O\%20DE\% 20JOVENS\%20 E\%2OADULTOS\%20COMO\%2OEXPRESS\%C3\%83O\%2O DA\%2OEDUCA\%C3\%87\%C3\%83O\%20POPULAR-\%20 A\%20CONTRIBUI\%C $3 \% 87 \% \mathrm{C}_{3} \% 83 \mathrm{O} \% 20 \mathrm{DO} \% 20 \mathrm{PEN}-$ SAMENTO\%20DE\%20PAULO\%2oFREIRE.pdf>. Acesso em: 14 nov. 2016.

MÉSZÁROS. Istvan. A Educação para Além do Capital. São Paulo: Boitempo; Editorila, 2005.

MORAES, Maria. C. Pensamento Eco-Sistêmico: educação, aprendizagem e cidadania no século XXI. 2. ed. Petrópolis: Vozes, 2008.

MORIN, Edgar. Os Sete Saberes necessários à Educação do Futuro. Brasília DF UNESCO, São Paulo: Ed. Cortez, 2003.

PASSOS, Ana Helena I.; VIEIRA, Camila C.; OLIVEIRA, Márcia M.; BIAZETTO, Márcia F. C. B. (Org.) Invisível e invizibilizado - ser negro no Brasil. Disponível em: $<$ www.geledes.org.br/areas-de-atuacao/questao-racial/ afrobrasileiros-e-suas-lutas/17948-invisivel-e-invizibilizado-ser-negro-no-brasil>. Acesso em: 14 nov. 2016.

PEREIRA, João Batista Borges. Diversidade e pluralidade: o negro na sociedade brasileira. Revista USP, São Paulo, n. 89, p. 278-284, mar./maio 2011.

RAMOS, Marise N.; ADÃO, Jorge M.; BARROS, Graciete M. N. (Coord.). Diversidade na educação: Reflexões e experiências. Brasília: Secretaria de Educação Média e Tecnológica, 2003.

SANSONE, Livio; PINHO, Osmundo Araujo (Org.). Raça: novas perspectivas antropológicas. 2 ed. rev. Salvador: Associação Brasileira de Antropologia; DUFBA, 2008.

SANTOS, Adilson Pereira dos. Itinerário das ações afirmativas no ensino superior público brasileiro: dos ecos de Durban à lei das cotas. Revista de C. Humanas, Viçosa, v. 12, n. 2, p. 289-317, jul./dez. 2012, 
SANTOS, Karla de Oliveira. A (In) Visibilidade Das Relações Étnico-Raciais No Livro Didático Da Educação De Jovens E Adultos. Disponível em: <http:// dmd2.webfactional.com/media/anais/A-(IN)-VISIBILIDADE-DAS-RELACOES-ETNICO-RACIAIS-NO-LIVRO-DIDATICO-DA-EDUCACAO-DE-JOVENS-E-ADULTOS. pdf $>$. Acesso em: 14 nov. 2016.

SAVIANI, Dermevel. Escola e democracia: Teorias da educação, curvatura da vara, onze teses sobre a educação política. Campinas: Autores Associados, 2000. (Coleção Polêmicas do Nosso Tempo, v. 5).

SILVA, José Afonso da. Curso de Direito Constitucional Positivo. 16. ed. São Paulo: Malheiros, 1999. P 397.

SILVA, Marcelo D. Educação Ideologia e Complexidade: contribuição para a crítica ao pensamento de Edgar Morin e sua interface com a educação brasileira Tese de Doutoramento. Campinas. Unicamp, 2010.

SILVA, Robson C.; CARVALHO, Marlene de Araújo. O Livro Didático como Instrumento de Difusão de Ideologias e o Papel do Professor Intelectual Transformador. 2012. Disponível em: <http://www.ufpi.br/ subsiteFiles/ppged/arquivos/files/eventos/evento2004/ GT.2/GT2_24_2004.pdf>. Acesso em: 14 nov. 2016

SOUZA, Neusa santos. Torna-se negro: as vicissitudes da identidade do negro brasileiro em ascensão social. Rio de Janeiro: Edições Graal, 1983. (Coleção Tendências, v. 4).

TEIXEIRA, Beatriz de Basto. Parâmetros Curriculares Nacionais, Plano Nacional De Educação e a Autonomia da Escola. Disponível em: <http://www.anped. org.br/reunioes/23/textos/o503t.pdf $>$. Acesso em: 14 nov. 2016.

WEBER, Max. Ética protestante e o espírito do capitalismo. Tradução de José marques Mariani de Macedo. São Paulo: Companhia das letras, 2004.

Recebido em: 26/12/2016

Aprovado em: 16/03/2016 